\title{
EXTRAÇÃO E EXPORTAÇÃO DE MACRONUTRIENTES EM LAVOURAS DE MILHO DE ALTA PRODUTIVIDADE
}

\author{
Thaísa Fernanda Oliveira* \\ Victor Jordão Braga Oliveira** \\ Junia Maria Clemente*** \\ Leonardo Angelo de Aquino***** \\ Marcelo Rodrigues dos Reis*** \\ Flavio Lemes Fernandes ${ }^{* * * * * *}$
}

RESUMO: O conhecimento da variabilidade da nutrição de plantas e da produtividade em áreas cultivadas com plantas de milho que apresentam alta produtividade pode fornecer importantes subsídios na racionalização do uso de insumos e auxiliar no manejo da fertilidade do solo. Essa pesquisa tem como objetivo determinar os padrões de extração e de exportação de nitrogênio $(\mathrm{N})$, fósforo $(\mathrm{P})$, potássio $(\mathrm{K})$, cálcio $(\mathrm{Ca})$, magnésio $(\mathrm{Mg})$ e enxofre $(\mathrm{S})$ por lavouras de milho de alta produtividade. Quinze talhões de milho cultivados sob sistema convencional e que apresentavam alto potencial produtivo foram amostrados no ano agrícola 2014/2015 na região do Alto Paranaíba $(\mathrm{MG})$ e avaliaram-se a produtividade e a extração e exportação de $\mathrm{N}, \mathrm{P}, \mathrm{K}, \mathrm{Ca}, \mathrm{Mg}$ e S. Os acúmulos de N, P, K e S em grãos e extração total tiveram efeitos positivos na produtividade da cultura do milho. A massa de mil grãos foi o componente de produtividade mais importante na definição da produtividade. A extração e exportação de $\mathrm{N}, \mathrm{P}, \mathrm{K}$ e $\mathrm{S}$ aumentaram linearmente com o aumento da produtividade. Os resultados fornecem dados importantes sobre a absorção e partição de nutrientes dos híbridos atuais e permitem aprimorar as recomendações de adubação para produção de grãos de milho.

PALAVRAS-CHAVE: Fertilidade; Grãos; Nutrição; Zea mays.

\footnotetext{
Departamento de Ciências Agrárias - Fitotecnia, Universidade Federal de Lavras, Brasil. E-mail: thaisafernanda135@gmail.com

** Engenheiro Agrônomo pela Universidade Federal de Viçosa, campus Rio Paranaíba, Brasil.

*** Doutorado em Fitotecnia pela Universidade Federal de Viçosa; Docente do Instituto Federal do Sudeste de Minas Gerais, Campus Manhuaçu, Brasil.

**** Doutorado em Fitotecnia pela Universidade Federal de Viçosa; Docente Adjunto IV da Universidade Federal de Viçosa, campus Rio Paranaíba, Brasil.

***** Doutorado em Fitotecnia pela Universidade Federal de Viçosa; Docente Adjunto IV da Universidade Federal de Viçosa, campus Rio Paranaíba, Brasil.

****** Doutorado pela Universidade Federal de Viçosa; Docente Adjunto IV da Universidade Federal de Viçosa, campus Rio Paranaíba, Brasil.
} 


\title{
EXTRACTION AND EXPORT OF MACRONUTRIENTS IN HIGH PRODUCTIVITY CORN
}

\begin{abstract}
Knowledge on the variability of plant nutrition and productivity in corn plantations with high productivity may provide important subsidies in the restructuring of inputs and in the management of soil fertility. Current research determines extraction and export standards of nitrogen, phosphorus, potassium, calcium, magnesium and sulfur in high productivity corn plantations. Fifteen corn rows cultivated within the traditional system, featuring high productivity, were sampled in the Alto Paranaíba, MG, Brazil, for the agricultural year 2014/2015, and the productivity, extraction and export of $\mathrm{N}, \mathrm{P}, \mathrm{K}, \mathrm{Ca}, \mathrm{Mg}$ and $\mathrm{S}$ were assessed. Accumulation of these macronutrients in the grains and total extraction had positive effects in corn productivity. Mass of one thousand grains was the most relevant productivity's component. N, P, K and S extraction and export increased linearly with increase of productivity. Results provide important data on the absorption and partition of nutrients of hybrids and allow the improvement of fertilizing recommendations for corn production.
\end{abstract}

KEY WORDS: Fertility; Grains; Nutrition; Zea mays.

\section{INTRODUÇÃO}

O milho (Zea mays L.) é o principal cereal produzido no Brasil. Na safra 2017/2018 estima-se, para o milho primeira e segunda safra, que a cultura será cultivada em aproximadamente 16 milhões de hectares, com produção próxima a 67 milhões de toneladas de grãos e produtividade média de 5,3 toneladas por hectare (CONAB, 2018).

A cultura apresenta alta exigência em macronutrientes e o manejo adequado dos fertilizantes é um dos principais fatores a contribuir para respostas positivas na produtividade. A extração e exportação de N, P, K, Ca, Mg e S é um dos indicadores da necessidade nutricional das plantas de milho e, assim, espera-se que quanto maior o rendimento de fitomassa maior seja a extração de nutrientes pela planta (SETIYONO et al., 2010).

Os manuais de recomendação, comumente utilizados para indicação 
de fertilizantes, são embasados em menores produtividades, pois são resultados de pesquisas feitas em décadas anteriores, com conjunto de tecnologias que possibilitavam produtividades menores que as obtidas atualmente (BENDER et al.; 2013). O avanço tecnológico nos últimos anos, caracterizado pelo uso de ferramentas de biotecnologia, híbridos geneticamente superiores, bem como a adoção de práticas agronômicas eficientes, tem levado a aumentos crescentes nas produtividades (BENDER et al., 2013).

Com o aumento na produtividade a demanda por macronutrientes segue a mesma tendência. Portanto, é primordial a reavaliação da extração e partição de nutrientes em lavouras com alto potencial produtivo com objetivo de otimizar o programa de adubação. Diante disso, o objetivo dessa pesquisa foi determinar os padrões de extração e de exportação de macronutrientes por lavouras de milho de alta produtividade.

\section{MATERIAL E MÉTODOS}

Quinze talhões de milho cultivados sob sistema convencional e que apresentavam alto potencial produtivo foram amostrados no ano agrícola 2014/2015 nos munícipios de Campos Altos, Rio Paranaíba e São Gotardo, localizados na região do Alto Paranaíba (MG) com altitudes variando entre 1.000 e 1.200 metros. Coordenadas e altitudes dos talhões: Lavouras 1 a 4 - 19²12'03" S 46010'11" W e altitude de $1131 \mathrm{~m}$; Lavouras 5 e 6 - 19²9'23" s 46011'41" W e altitude de 1186 m; Lavouras 7 a 11 - 19²'26" s 4607'08" W e altitude de $1111 \mathrm{~m}$; Lavoura 12 - 19014'23" s 46018'46" W e altitude de 944 m; Lavoura 13 a 15 - 19¹6'38" s $46^{\circ} 18^{\prime} 32^{\prime \prime}$ W e altitude de $912 \mathrm{~m}$. Nesses talhões, já se cultivavam olerícolas (cenoura, cebola, alho e batata) em rotação com grandes culturas (milho, soja e trigo).

O solo de todos os talhões é classificado como Latossolo Vermelho-Amarelo de textura muito argilosa (EMBRAPA, 2013). O clima segundo a classificação internacional de Köppen é do tipo Aw, definido como tropical com estação seca. As caraterísticas químicas do solo das lavouras amostradas estão apresentadas na Tabela 1 (alguns talhões estavam no mesmo solo e a diferença entre eles era o híbrido 
de milho e a população). As principais características das unidades amostrais estão sumarizadas na Tabela 2 e os dados meteorológicos para a região na Figura 1.

Tabela 1 - Análise química dos solos na camada de 0 a $20 \mathrm{~cm}$ de profundidade

\begin{tabular}{|c|c|c|c|c|c|c|c|c|}
\hline \multirow{2}{*}{ Análises } & \multirow{2}{*}{ Unidades } & \multicolumn{7}{|c|}{ Solos } \\
\hline & & 1 & 2 & 3 & 4 & 5 & 6 & 7 \\
\hline $\mathrm{pH}\left(\mathrm{H}_{2} \mathrm{O}\right)$ & . & 5.5 & 6.3 & 6.3 & 6.5 & 5.5 & 6.2 & 5.4 \\
\hline M.O. & dag $\mathrm{kg}^{-1}$ & 3.2 & 4.1 & 2.6 & 2.2 & 2.4 & 2.4 & 3.9 \\
\hline P-rem & $\mathrm{mg} \mathrm{l}^{-1}$ & 24.7 & 13.0 & 13.0 & 14.4 & 15.8 & 11.3 & 30.2 \\
\hline P (Mehlich-1) & $\mathrm{mg} \mathrm{dm}{ }^{-3}$ & 10.5 & 51.0 & 45.0 & 17.2 & 10.4 & 43.7 & 26.9 \\
\hline $\mathrm{K}$ & $\mathrm{mg} \mathrm{dm}^{-3}$ & 131 & 137 & 125 & 64 & 91 & 253 & 112 \\
\hline $\mathrm{Ca}^{2+}$ & $\mathrm{cmol}_{\mathrm{c}} \mathrm{dm}^{-3}$ & 3.2 & 4.3 & 4.3 & 5.2 & 3.0 & 3.8 & 3.5 \\
\hline $\mathrm{Mg}^{2+}$ & $\mathrm{cmol}_{\mathrm{c}} \mathrm{dm}^{-3}$ & 0.9 & 1.1 & 0.6 & 1.3 & 0.9 & 0.8 & 0.9 \\
\hline$S$ & $\mathrm{mg} \mathrm{dm}^{-3}$ & 29 & 54 & 18 & 24 & 29 & 12 & 19 \\
\hline $\mathrm{Al}^{3+}$ & $\mathrm{cmol}_{\mathrm{c}} \mathrm{dm}^{-3}$ & 0.27 & 0 & 0 & 0 & 0.2 & 0 & 0.32 \\
\hline $\mathrm{H}+\mathrm{Al}$ & $\mathrm{cmol}_{\mathrm{c}} \mathrm{dm}^{-3}$ & 6.10 & 3.65 & 3.24 & 2.60 & 5.60 & 2.83 & 6.59 \\
\hline SB & $\mathrm{cmol}_{\mathrm{c}} \mathrm{dm}^{-3}$ & 4.43 & 5.75 & 5.22 & 6.66 & 4.13 & 5.25 & 4.46 \\
\hline $\mathrm{t}$ & $\mathrm{cmol}_{\mathrm{c}} \mathrm{dm}^{-3}$ & 4.70 & 5.75 & 5.22 & 6.66 & 4.33 & 5.25 & 5.01 \\
\hline $\mathrm{T}$ & $\mathrm{cmol}_{\mathrm{c}} \mathrm{dm}^{-3}$ & 10.53 & 9.40 & 8.46 & 9.26 & 9.73 & 8.08 & 11.28 \\
\hline B & $\mathrm{mg} \mathrm{dm}^{-3}$ & 0.7 & 0.9 & 0.9 & 0.7 & 0.7 & 1.1 & 0.7 \\
\hline $\mathrm{Zn}$ & $\mathrm{mg} \mathrm{dm}{ }^{-3}$ & 1.4 & 8.4 & 8.6 & 1.4 & 1.2 & 10.6 & 3.1 \\
\hline $\mathrm{Fe}$ & $\mathrm{mg} \mathrm{dm}^{-3}$ & 32.0 & 42.0 & 45.0 & 30.0 & 31.0 & 25.2 & 30.0 \\
\hline $\mathrm{Mn}$ & $\mathrm{mg} \mathrm{dm}^{-3}$ & 5.9 & 5.3 & 7.1 & 11.7 & 11.3 & 14.9 & 16.9 \\
\hline $\mathrm{Cu}$ & $\mathrm{mg} \mathrm{dm}^{-3}$ & 3.5 & 7.8 & 3.2 & 1.2 & 1.2 & 7.3 & 2.0 \\
\hline
\end{tabular}

Extratores: P - Resina; P e K - Mehlich - 1; Ca, Mg e Al - KCl 1 mol L $^{-1}$; B - água quente; Cu, $\mathrm{Fe}, \mathrm{Mn} \mathrm{e}$ Zn - DTPA pH 7,3; S-SO - Fosfato Monobásico cálcio $0.01 \mathrm{~mol} \mathrm{~L}^{-1}$; M.O. = Método Walkley-Black. 
Tabela 2. Características das unidades amostrais

\begin{tabular}{|c|c|c|c|c|c|c|c|c|c|c|c|}
\hline \multirow[t]{2}{*}{ 弑 } & \multirow[t]{2}{*}{ 응 } & \multirow{2}{*}{ 을 } & \multirow{2}{*}{ 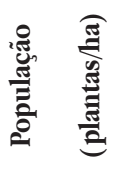 } & \multirow{2}{*}{ 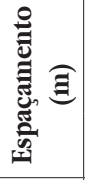 } & \multirow[t]{2}{*}{$\mathscr{a}$} & \multirow[t]{2}{*}{ U } & \multicolumn{3}{|c|}{$\begin{array}{c}\text { AS } \\
\left(\mathrm{kg} \mathrm{ha}^{-1}\right)\end{array}$} & \multicolumn{2}{|c|}{$\begin{array}{c}\mathrm{AC} \\
\left(\mathrm{kg} \mathrm{ha}^{-1}\right)\end{array}$} \\
\hline & & & & & & & $\mathrm{N}$ & $\mathrm{P}_{2} \mathrm{O}_{5}$ & $\mathrm{~K}_{2} \mathrm{O}$ & $\mathrm{N}$ & $\mathrm{K}_{2} \mathrm{O}$ \\
\hline 1 & 1 & P30F53YH & 68500 & 0,6 & $28 / 10$ & $19 / 04$ & 28 & 105 & 35 & 165 & 0 \\
\hline 2 & 1 & P3456H & 66700 & 0,6 & $28 / 10$ & $19 / 04$ & 28 & 105 & 35 & 165 & 0 \\
\hline 3 & 1 & Р3779H & 69200 & 0,6 & $28 / 10$ & $19 / 04$ & 28 & 105 & 35 & 165 & 0 \\
\hline 4 & 1 & $\mathrm{P} 3630 \mathrm{H}$ & 65000 & 0,6 & $28 / 10$ & $19 / 04$ & 28 & 105 & 35 & 165 & 0 \\
\hline 5 & 2 & P30F53YH & 63750 & 0,8 & $25 / 10$ & $26 / 04$ & 20 & 94 & 00 & 216 & 60 \\
\hline 6 & 3 & P30F53YH & 68500 & 0,8 & $15 / 10$ & $12 / 04$ & 20 & 94 & 00 & 216 & 60 \\
\hline 7 & 4 & P3456H & 70500 & 0,5 & $23 / 10$ & $02 / 05$ & 24 & 90 & 30 & 184 & 150 \\
\hline 8 & 4 & Р3779H & 83500 & 0,5 & $23 / 10$ & $02 / 05$ & 24 & 90 & 30 & 184 & 150 \\
\hline 9 & 4 & $\mathrm{P} 3630 \mathrm{H}$ & 80000 & 0,5 & $23 / 10$ & $02 / 05$ & 24 & 90 & 30 & 184 & 150 \\
\hline 10 & 5 & 2B810 Pw & 66400 & 0,5 & $23 / 10$ & $02 / 05$ & 24 & 90 & 30 & 170 & 80 \\
\hline 11 & 5 & DKB310VTPro 2 & 65000 & 0,5 & $23 / 10$ & $02 / 05$ & 24 & 90 & 30 & 170 & 80 \\
\hline 12 & 6 & P30F53YH & 65500 & 0,5 & $20 / 10$ & $25 / 03$ & 18 & 66 & 22 & 126 & 0 \\
\hline 13 & 7 & P30F53YH & 66500 & 0,5 & $25 / 10$ & $05 / 05$ & 32 & 126 & 72 & 113 & 0 \\
\hline 14 & 7 & $30 \mathrm{~A} 37 \mathrm{Pw}$ & 71500 & 0,5 & $25 / 10$ & $05 / 05$ & 32 & 126 & 72 & 113 & 0 \\
\hline 15 & 7 & DKB310 VTPro 2 & 70500 & 0,5 & $25 / 10$ & $05 / 05$ & 32 & 126 & 72 & 113 & 0 \\
\hline
\end{tabular}

Data de semeadura (DS); Data de colheita (DC); Adubação de semeadura (AS); Adubação de cobertura $(\mathrm{AC})$.

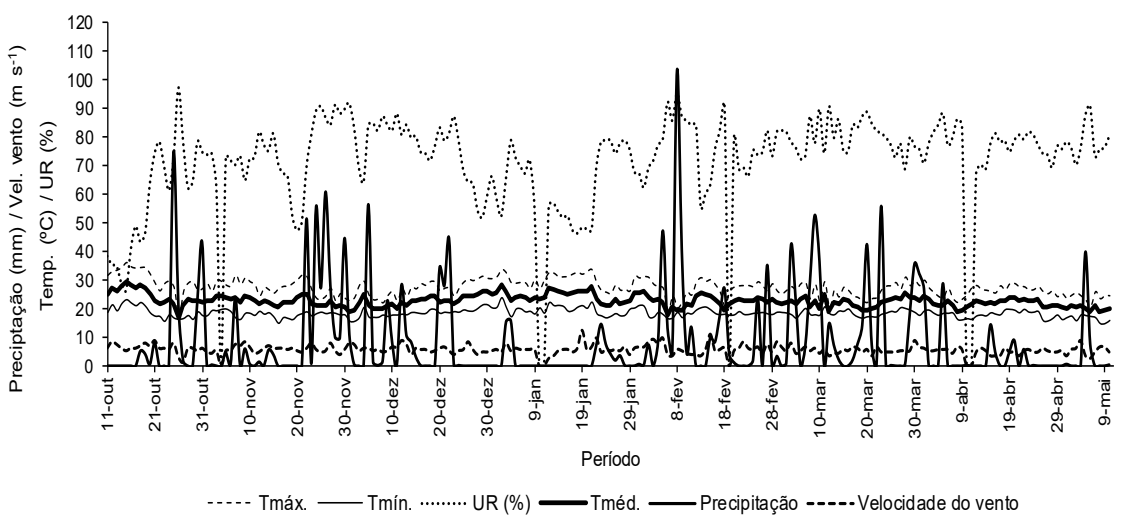

Figura 1. Precipitação, velocidade do vento, temperatura máxima (Tmáx.), temperatura mínima (Tmín.), temperatura média (Tméd.) e umidade relativa do ar (UR\%) para a região do Alto Paranaíba (MG), no período de outubro de 2014 a maio de 2015. 
Foram coletadas plantas na fase de maturidade fisiológica para determinação da matéria seca e extração de macronutrientes. Em cada área selecionada foram amostras 20 plantas em cinco pontos. Em cada ponto, quatro plantas consecutivas foram cortadas rente ao solo. Os pontos estavam inseridos em uma subárea homogênea do talhão de 50 x $50 \mathrm{~m}$. As plantas de milho foram subdivididas em material produtivo (grãos) e material vegetativo (folhas, colmo, pendão, sabugo e folha modificada da espiga). O material vegetativo foi picado em picador forrageiro, homogeneizado, pesado e em seguida retirou-se uma sub-amostra.

Os grãos também foram pesados e retirada uma sub-amostra. Para eliminação total da umidade, as sub-amostras de material vegetativo e grãos foram acondicionadas em estufa com circulação forçada de ar à temperatura de $70{ }^{\circ} \mathrm{C}$ durante 72 h até a obtenção da massa constante. Em seguida, as sub-amostras foram pesadas para obter a matéria seca (grãos, vegetativa e total) e os valores extrapolados para se obter a massa por hectare.

A produtividade foi estimada pela coleta de 20 plantas e de suas espigas, que foram debulhadas e retirada uma amostra de 500 gramas que após seca em estufa foi pesada e extrapolada a produção por hectare. Determinaram-se também o número de fileiras por espiga (FE), o número de grãos por fileira (GF) e o número de grãos por espiga que foi obtido pelo produto entre FE e GF. A massa de 1000 grãos foi obtida pela contagem manual de quatro repetições de 250 grãos, os quais foram secos até detecção da massa constante e realizada a pesagem em balança de precisão. Para as variáveis massa de mil grãos e produtividade a umidade foi corrigida para $13 \%$ de base úmida.

Após a secagem, o material vegetal foi triturado em moinho Wiley equipado com peneira de 1,27 mm para determinação dos teores de $\mathrm{N}, \mathrm{P}, \mathrm{K}, \mathrm{Ca}, \mathrm{Mg}$ e $\mathrm{S}$ de acordo com métodos descritos em Malavolta et al. (1997). Os conteúdos de N, P, K, $\mathrm{Ca}, \mathrm{Mg}$ e $\mathrm{S}$ na parte vegetativa e grãos foram estimados pelo produto entre os teores dos respectivos nutrientes e o rendimento de matéria seca e expressos em $\mathrm{kg} \mathrm{ha}^{-1}$.

$O$ índice de colheita, com base na matéria seca, foi calculado pela razão entre a produção de matéria seca de grãos e a massa da matéria seca total. Os índices de colheita dos macronutrientes foram calculados pela razão entre o acúmulo do respectivo nutriente nos grãos pelo acúmulo total na planta. 
Os dados obtidos foram submetidos à análise de estatística descritiva para obter a média, valores máximos e mínimos e coeficiente de variação. A medida da correlação linear do coeficiente de Pearson serviu para determinar a relação entre as variáveis analisadas, a 5\% de probabilidade. Ajustaram-se as equações de regressão para explicar a variação da extração e exportação de macronutrientes em função da produtividade de grãos.

\section{RESULTADOS E DISCUSSÃO}

A análise descritiva da produtividade, bem como das variáveis do crescimento vegetativo nas plantas de milho apresentaram coeficientes de variação (CVs) relativamente baixos, o que caracteriza homogeneidade dos dados (Tabela 03). Quanto aos acúmulos de N, P, K, Ca e Mg nos grãos e na parte vegetativa os CVs mais elevados indicam efeitos de fatores relacionados aos diferentes híbridos, a exemplo da potencialidade genética, da quantidade de carboidratos produzida, da intensidade transpiratória e morfologia das raízes (BENDER et al., 2013).

Tabela 3. Estatística descritiva da produtividade, população de plantas, número de fileiras por espiga, número de grãos por fileira, número de grãos por espiga, massa de mil grãos, massa seca vegetativa, massa seca total, acúmulos de N, P, K, Ca, Mg e S na parte vegetativa, nos grãos e total, índices de colheita para o N, P, K, Ca, Mg e S em plantas de milho e índices de colheita de grãos

(Continua)

\begin{tabular}{l|c|c|c|c}
\hline Variáveis & Mínimo & Média & Máximo & CV \\
\hline Produtividade $\left(\mathrm{t} \mathrm{ha}^{-1}\right)$ & 13 & 15 & 18 & 8.8 \\
\hline População de plantas & 63.750 & 69.403 & 83.500 & 7.9 \\
\hline Fileiras por espiga & 15 & 17 & 20 & 10.2 \\
\hline Grãos por fileira & 31 & 36 & 40 & 8.1 \\
\hline Grãos por espiga & 551 & 628 & 720 & 8.2 \\
\hline Massa de mil grãos $(\mathrm{g})$ & 243 & 319 & 353 & 9.9 \\
\hline Massa seca vegetativa $\left(\mathrm{kg} \mathrm{ha}^{-1}\right)$ & 10.293 & 12.320 & 15.696 & 11.6 \\
\hline Massa seca total $\left(\mathrm{kg} \mathrm{ha}^{-1}\right)$ & 21.207 & 25.646 & 29.259 & 7.8 \\
\hline Índice de colheita de grãos $\left(\mathrm{kg} \mathrm{kg}^{-1}\right)$ & 0.46 & 0.52 & 0.57 & 4.7 \\
\hline
\end{tabular}


(Conclusão)

\begin{tabular}{l|c|c|c|c}
\hline Variáveis & Mínimo & Média & Máximo & CV \\
\hline $\mathrm{N}$ acumulado na parte vegetativa $\left(\mathrm{kg} \mathrm{ha}^{-1}\right)$ & 49 & 68 & 105 & 20.2 \\
\hline $\mathrm{N}$ acumulado nos grãos $\left(\mathrm{kg} \mathrm{ha}^{-1}\right)$ & 107 & 148 & 203 & 14.9 \\
\hline $\mathrm{N}$ acumulado total $\left(\mathrm{kg} \mathrm{ha}^{-1}\right)$ & 155 & 216 & 254 & 12.8 \\
\hline P acumulado na parte vegetativa $\left(\mathrm{kg} \mathrm{ha}^{-1}\right)$ & 3 & 6 & 9 & 28.1 \\
\hline P acumulado nos grãos $\left(\mathrm{kg} \mathrm{ha}^{-1}\right)$ & 35 & 58 & 92 & 25.8 \\
\hline P acumulado total $\left(\mathrm{kg} \mathrm{ha}^{-1}\right)$ & 37 & 64 & 98 & 28.1 \\
\hline K acumulado na parte vegetativa $\left(\mathrm{kg} \mathrm{ha}^{-1}\right)$ & 95 & 181 & 246 & 23.4 \\
\hline K acumulado nos grãos $\left(\mathrm{kg} \mathrm{ha}^{-1}\right)$ & 61 & 72 & 111 & 17.9 \\
\hline K acumulado total $\left(\mathrm{kg} \mathrm{ha}^{-1}\right)$ & 157 & 253 & 324 & 17.3 \\
\hline Ca acumulado na parte vegetativa $\left(\mathrm{kg} \mathrm{ha}^{-1}\right)$ & 30 & 42 & 62 & 22.5 \\
\hline Ca acumulado nos grãos $\left(\mathrm{kg} \mathrm{ha}^{-1}\right)$ & 6 & 13 & 35 & 65.8 \\
\hline Ca acumulado total $\left(\mathrm{kg} \mathrm{ha}^{-1}\right)$ & 38 & 55 & 71 & 20.3 \\
\hline Mg acumulado na parte vegetativa $\left(\mathrm{kg} \mathrm{ha}^{-1}\right)$ & 16 & 25 & 38 & 28.8 \\
\hline Mg acumulado nos grãos $\left(\mathrm{kg} \mathrm{ha}^{-1}\right)$ & 15 & 24 & 35 & 24.7 \\
\hline Mg acumulado total $\left(\mathrm{kg} \mathrm{ha}^{-1}\right)$ & 36 & 48 & 64 & 18.2 \\
\hline $\mathrm{S}$ acumulado na parte vegetativa $\left(\mathrm{kg} \mathrm{ha}^{-1}\right)$ & 4 & 4 & 6 & 12.5 \\
\hline S acumulado nos grãos $\left(\mathrm{kg} \mathrm{ha}^{-1}\right)$ & 4 & 5 & 6 & 10.3 \\
\hline S acumulado total $\left(\mathrm{kg} \mathrm{ha}^{-1}\right)$ & 8 & 9 & 11 & 8.1 \\
\hline Índice de colheita do N $\left(\mathrm{kg} \mathrm{kg}^{-1}\right)$ & 0.59 & 0.69 & 0.80 & 6.4 \\
\hline Índice de colheita do P $\left(\mathrm{kg} \mathrm{kg}^{-1}\right)$ & 0.86 & 0.91 & 0.94 & 2.3 \\
\hline Índice de colheita do K $\left(\mathrm{kg} \mathrm{kg}^{-1}\right)$ & 0.22 & 0.29 & 0.44 & 22.0 \\
\hline Índice de colheita do Ca $\left(\mathrm{kg} \mathrm{kg}^{-1}\right)$ & 0.1 & 0.2 & 0.5 & 47.3 \\
\hline Índice de colheita do Mg $\left(\mathrm{kg} \mathrm{kg}^{-1}\right)$ & 0.3 & 0.5 & 0.7 & 20 \\
\hline Índice de colheita do S $\left(\mathrm{kg} \mathrm{kg}^{-1}\right)$ & 0.4 & 0.5 & 0.5 & 6.9 \\
\hline Índice de colheita dos grãos (kg kg-1) & & & & 4.7 \\
\hline $\mathrm{CV}$ - & & & \\
\hline
\end{tabular}

CV - coeficiente de variação.

A produtividade média do milho nos talhões amostrados foi de $15 \mathrm{t} \mathrm{ha}^{-1}$ com valores mínimo e máximo de 13 e $18 \mathrm{t} \mathrm{ha}^{-1}$ (Tabela 3). Essa produtividade média é expressivamente superior à média nacional $\left(5,3 \mathrm{tha}^{-1}\right)$ e à média no Estado de Minas Gerais (6,3 t ha-1) (CONAB, 2018). Esse alto rendimento do milho nas lavouras amostradas deveu-se à combinação de boas práticas agronômicas, a 
exemplo da adequada nutrição das plantas, híbridos de alto potencial produtivo, ajuste adequado de população, solos de alta fertilidade e época de cultivo favorável à cultura.

Os índices de colheita para o N, P, K, Ca, Mg e S apresentaram médias de $0.69,0.91,0.29,0.2,0.5$ e $0.5 \mathrm{~kg} \mathrm{~kg}^{-1}$ (Tabela 3). Assim, há maior remoção de $\mathrm{N}$ e de $\mathrm{P}$ da área de cultivo pelos grãos colhidos em relação aos demais nutrientes. No caso do K, a maior parte é acumulada na parte vegetativa e devido a isso é restituído ao solo após a colheita com a incorporação dos restos culturais do milho (ZÖRB et al., 2014). Como o K não faz parte da estrutura de compostos orgânicos nas plantas é facilmente liberado ao solo com a fragmentação dos resíduos e com a lavagem pela água da chuva (ZÖRB et al., 2014).

Em pesquisa realizada nos Estados Unidos com híbridos de milho de alta produtividade, Bender et al. (2013) obtiveram os índices de colheita $\left(\mathrm{kg} \mathrm{kg}^{-1}\right)$ de $\mathrm{N}, \mathrm{P}, \mathrm{K}, \mathrm{Ca}, \mathrm{Mg}$ de $0.58,0.79,0.33,0.29$ e S 0.57 , cujas exportações para os grãos foram de 166, 90, 66, 17 e $15 \mathrm{~kg} \mathrm{ha}^{-1}$, respectivamente. Isso demonstra a necessidade de compreender onde, quando e como os nutrientes são utilizados pelas plantas e também a necessidade de restituir ao solo os nutrientes exportados pela cultura, a fim de não causar empobrecimento ao mesmo para cultivos futuros.

A produtividade apresentou correlação positiva e significativa com a massa de mil grãos, no entanto, não apresentou correlação significativa com população de plantas, número de fileiras por espiga, número de grãos por fileira e número de grãos por espiga (Tabela 4). A massa de mil grãos é influenciada pelo acúmulo de fotoassimilados durante o crescimento vegetativo no colmo que são translocados na fase de enchimento de grãos e, junto com os fotoassimilados produzidos nessa fase, completam o enchimento dos grãos (BRITO et al., 2013). 
Tabela 4. Coeficientes de correlação de Pearson da produtividade (PRO), população de plantas de milho (POP), número de fileiras por espiga (FE), número de grão por fileira (GF), número de grãos por espiga (GE), massa de mil grãos (M1000), matéria seca vegetativa (MSV) e matéria seca total (MST)

\begin{tabular}{l|l|l|l|l|l|l|l|l}
\hline Variáveis & PRO & POP & FE & GF & GE & M1000 & MSV & MST \\
\hline PRO & 1 & 0.0414 & -0.192 & -0.0109 & -0.216 & $0.68^{* *}$ & 0.387 & $0.822^{* *}$ \\
\hline POP & & 1 & 0.368 & $-0.743^{* *}$ & -0.328 & -0.228 & 0.175 & 0.132 \\
\hline FE & & & 1 & $-0.655^{* *}$ & $0.615^{*}$ & $-0.642^{* *}$ & 0.224 & 0.026 \\
\hline GF & & & & 1 & 0.189 & 0.232 & -0.479 & -0.302 \\
\hline GE & & & & & 1 & $-0.573^{*}$ & -0.178 & -0.235 \\
\hline M1000 & & & & & & 1 & 0.35 & $0.612^{*}$ \\
\hline MSV & & & & & & & 1 & $0.844^{* *}$ \\
\hline MST & & & & & & & & 1 \\
\hline
\end{tabular}

*Significativo a 5\% de probabilidade; ** Significativo a 1\% de probabilidade.

$\mathrm{O}$ número de fileiras por espiga apresentou correlação significativa e negativa com o número de grãos por fileira e massa de mil grãos (Tabela 4). Quanto aos grãos por espiga essa correlação foi positiva, dado que quanto maior o número de fileiras por espiga espera-se maior número de grãos por espiga. No entanto, as massas individuais dos grãos juntamente ao número de grãos por fileira deverão ser menores devido à menor quantidade de fotoassimilados destinados à formação dos grãos (BRITO et al., 2013).

A população de plantas correlacionou-se negativamente com o número de grãos por fileira (Tabela 4). Argenta et al. (2001) verificaram que o aumento da população de plantas proporcionou menor número de grãos por espiga, havendo um decréscimo linear com o aumento no espaçamento entre linhas. Populações muito altas podem retardar o aparecimento dos estigmas e dos estiletes mais que a liberação do pólen, especialmente sob condições adversas (água), afetando assim a fecundação e, consequentemente, a formação dos grãos. Borghi et al. (2004) afirmam que para uma população de 55.000 plantas ha ${ }^{-1}$ houve maior massa de grãos por espiga, e destacam a influência de condições favoráveis na época do florescimento, uma vez que temperatura alta e baixa precipitação pluvial diminuíram a quantidade de grãos formados nas maiores populações, em razão da maior competição por 
recursos entre as plantas, refletindo nos menores valores de massa de grãos por espiga.

A matéria seca vegetativa correlacionou positivamente com a matéria seca total (Tabela 4). A falta de correlação entre matéria seca vegetativa e produtividade pode estar relacionada aos índices de colheita distintos dos híbridos de milho. Híbridos com alta matéria seca vegetativa podem apresentar baixo índice de colheita (matéria seca de grãos), o que significa menor eficiência de conversão de fotoassimilados em grãos (BENDER et al., 2013; BRITO et al., 2013).

Maiores acúmulos de N, P, K, Mg e S nos grãos, bem como com a extração total do N, P, K e S resultaram em produtividades superiores (Tabela 5). Plantas bem nutridas são mais eficientes na absorção dos nutrientes em geral, devido ao maior crescimento do sistema radicular e melhor eficiência de rotas metabólicas da planta com resultados positivos na produtividade (MONTEZANO et al., 2008).

Tabela 5. Coeficientes de correlação de Pearson da produtividade com N, P, K, Ca, Mg e S acumulados em parte vegetativa, grãos e total

(Continua)

\begin{tabular}{l|c}
\hline Variáveis & Produtividade \\
\hline N acumulado na parte vegetativa & 0.169 \\
\hline N acumulado em grãos & $0.932^{* *}$ \\
\hline Extração total de N & $0.829^{* *}$ \\
\hline P acumulado na parte vegetativa & 0.391 \\
\hline P acumulado em grãos & $0.663^{* *}$ \\
\hline Extração total de P & $0.664^{* *}$ \\
\hline K acumulado na parte vegetativa & 0.400 \\
\hline K acumulado em grãos & $0.743^{* *}$ \\
\hline Extração total de K & $0.606^{*}$ \\
\hline Ca acumulado na parte vegetativa & -0.165 \\
\hline Ca acumulado em grãos & -0.107 \\
\hline Extração total de Ca & -0.221 \\
\hline Mg acumulado na parte vegetativa & -0.088 \\
\hline Mg acumulado em grãos & $0.541^{*}$ \\
\hline Extração total de Mg & 0.286 \\
\hline
\end{tabular}


(Conclusão)

\begin{tabular}{l|c}
\hline Variáveis & Produtividade \\
\hline S acumulado na parte vegetativa & 0.191 \\
\hline S acumulado em grãos & $0.674^{* *}$ \\
\hline Extração total de S & $0.604^{*}$ \\
\hline Índice de colheita dos grãos & 0.472 \\
\hline * Significativo a 5\% de probabilidade; ** Significativo a 1\% de probabilidade. \\
\hline
\end{tabular}

Os acúmulos totais de $\mathrm{N}$ e $\mathrm{P}$ e em grãos aumentaram linearmente com o aumento da produtividade (Figura 2); em parte vegetativa o acúmulo de $\mathrm{N}$ e $\mathrm{P}$ não variou com a produtividade e as médias gerais foram de $68 \mathrm{e} 6 \mathrm{~kg} \mathrm{ha}^{-1}$, respectivamente. Isto indica que a alta capacidade de exportação de $\mathrm{N}$ e $\mathrm{P}$ dos híbridos é determinante para altas produtividades. Com relação aos acúmulos totais de $\mathrm{K}$, em parte vegetativa e em grãos, estes aumentaram linearmente com o aumento da produtividade (Figura 2).

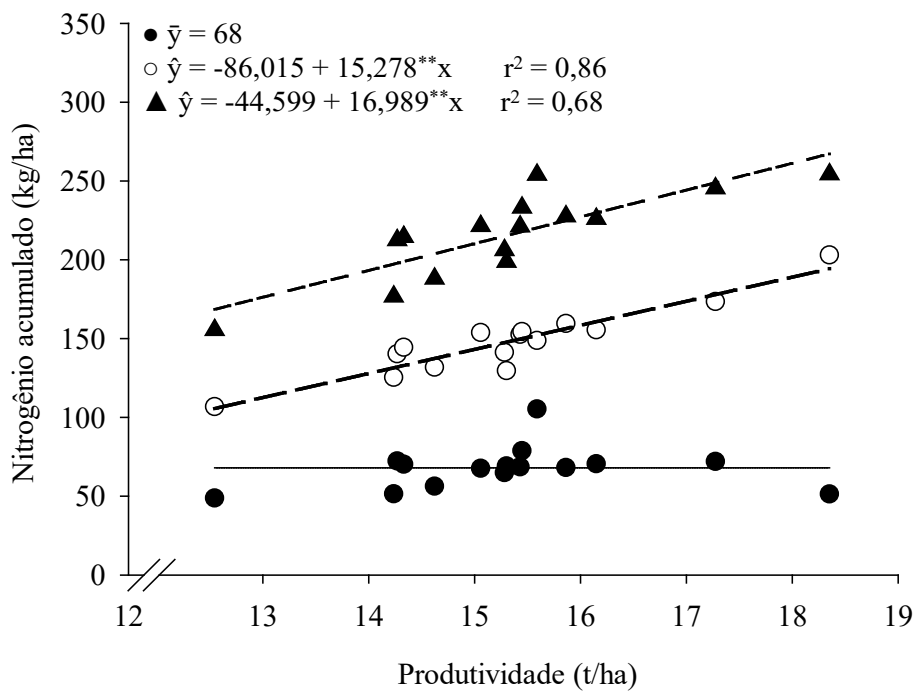



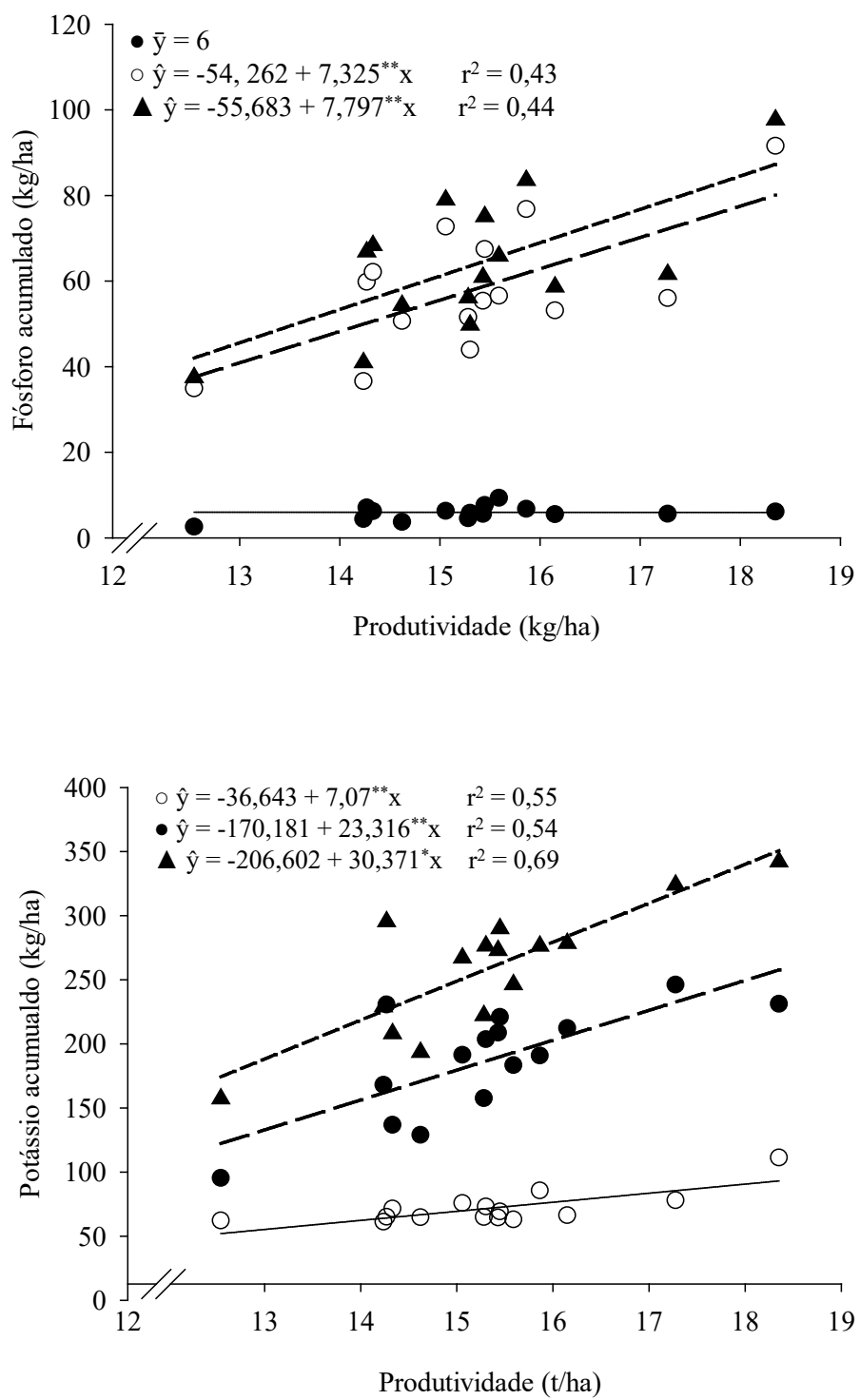

Figura 2. Nitrogênio, fósforo e potássio acumulados na parte vegetativa (•), grãos (০) e na planta inteira $(\boldsymbol{\Delta})$ em função da produtividade do milho 
Houve alta extração e exportação de N (Figura 2). O P é extraído em menor proporção comparativamente ao $\mathrm{N}$ e ao $\mathrm{K}$, porém é fortemente exportado. O K é altamente extraído, porém a exportação é baixa, indicando a alta capacidade de reciclagem de $\mathrm{K}$ pelo milho (Figura 2). O N e o $\mathrm{P}$, juntamente com o $\mathrm{K}$ (pela sua alta extração), merecem atenção especial e devem ser atendidos prioritariamente na adubação de reposição para que não se empobreça o solo.

A relação linear entre acúmulos de NPK (na planta inteira) e em grãos com a produtividade (Figura 2), sugere que a produtividade pode ser incrementada pela adição de maiores doses de fertilizantes. No entanto, deve-se atentar para o fato de que doses excessivas, principalmente de $\mathrm{N}$, podem causar danos ambientais relacionados à perda de $\mathrm{N}$ na forma de $\mathrm{N}_{2} \mathrm{O}$ gasoso e de $\mathrm{NO}_{3}$ que pode lixiviar para o lençol freático (PRIMAVESI et al., 2006). Sichocki et al. (2014) afirmam que doses de $\mathrm{N}$ e de $\mathrm{P}$ não influenciaram o número de fileiras de grãos por espiga no cultivo de milho safrinha, no entanto, o número de grãos por fileira, o teor foliar de N, o teor foliar de $\mathrm{P}$ e a massa de mil grãos apresentaram aumento linear em resposta às doses de N. O aumento do número de grãos por fileira contribui para aumento da produtividade e o alto teor de $\mathrm{N}$ e de $\mathrm{P}$ contribui para maior taxa fotossintética e enchimento dos grãos, especialmente na fase reprodutiva.

Com relação ao K, a aplicação insuficiente de adubo potássico pode levar ao esgotamento das reservas do solo; já a aplicação excessiva pode intensificar as perdas por lixiviação, mesmo em solos com média e alta capacidades de troca catiônica, além de competir com os demais macronutrientes catiônicos pelos sítios de absorção (ERNANI et al., 2007).

Os acúmulos de Ca e Mg não variaram com a produtividade crescente, sendo as extrações médias totais de 54.82 e $48.29 \mathrm{~kg} \mathrm{ha}^{-1}$, respectivamente. Os resultados obtidos quanto ao Ca e Mg sugerem que os solos já apresentavam quantidades suficientes para suprir as necessidades das plantas de milho, sendo que nos talhões amostrados já se cultivavam olerícolas (cenoura, cebola, alho e batata) em que a aplicação de corretivos e fertilizantes é bastante elevada.

A extração total de S e o acúmulo desse nutriente nos grãos aumentaram linearmente com o aumento da produtividade. A aplicação de fórmulas comerciais de fertilizantes com altas concentrações NPK, a exemplo do superfosfato triplo, 
utilizam matéria-prima pobre em $\mathrm{S}$ e podem causar a deficiência do nutriente em solos pobres em matéria orgânica ou quando a extração do nutriente é alta em lavouras com alta produtividade.

Setiyono et al. (2010) mensuraram que para obtenção de uma produtividade de $15 \mathrm{t} \mathrm{ha}^{-1}$ de grãos de milho, demandam, em média, $257 \mathrm{~kg}$ de $\mathrm{N}, 37 \mathrm{~kg}$ de $\mathrm{P}$ e $249 \mathrm{~kg}$ de $\mathrm{K}$, dos quais 64\%, 84\% e 17\% são exportados para o grão. Esses valores de extração e exportação de $\mathrm{N}$ e $\mathrm{K}$ foram próximos aos encontrados no presente trabalho, porém, os valores de extração de $\mathrm{P}$ foram mais baixos (64 kg de P).

Valderrama et al. (2011) verificaram aumento linear do número de grãos até a dose de $120 \mathrm{~kg} \mathrm{ha}^{-1}$ de $\mathrm{K}_{2} \mathrm{O}$. Sangoi et al. (2007) observaram que o maior número de grãos por espiga foi característica definida em grande parte pelo híbrido. Portanto, além da nutrição, o híbrido correto deve ser selecionado na busca do maior número de grãos e, por conseguinte, maior produtividade.

Santos et al. (2013) observaram incrementos lineares na matéria seca foliar em função das doses de $\mathrm{N}$ aplicadas tanto em sistema de plantio convencional quanto sistema de plantio direto, assim como nos teores e conteúdos foliares de $\mathrm{N}$ em ambos os sistemas de cultivo. Esses autores verificaram incrementos em produtividade com a aplicação de até $340 \mathrm{~kg} \mathrm{ha}^{-1}$ de $\mathrm{N}$ em áreas de alta fertilidade com a obtenção de produtividades próximas a $17 \mathrm{t} \mathrm{ha}^{-1}$.

\section{CONSIDERAÇÕES FINAIS}

Os acúmulos de N, P, K e S em grãos e extração total tiveram efeitos positivos na produtividade da cultura do milho. A massa de mil grãos foi o componente de produtividade mais importante na definição da produtividade. A extração e exportação de N, P, K e S aumentam linearmente com o aumento da produtividade.

Os resultados fornecem dados importantes sobre a absorção e partição de nutrientes dos híbridos atuais e permitem aprimorar as recomendações de adubação para produção de grãos de milho. As informações obtidas indicam a relação linear no aumento da extração de N, P e K pelo milho para aumentar a produtividade de grãos até aproximadamente $18 \mathrm{t} \mathrm{ha}{ }^{-1}$. Além da adoção de boas práticas de rotação de 
culturas, da qualidade do solo, operações mecanizadas e da escolha de híbridos de milho com alto potencial produtivo e adaptados ao ambiente de cultivo, deve haver atenção especial às adubações para o incremento de produtividade do milho nos próximos anos.

\section{REFERÊNCIAS}

ARGENTA, G.; SILVA, P. R. F.; BORTOLINI, C. G.; FORSTHOFER, E. L.; STRIEDER, M. L. Relação da leitura do clorofilômetro com os teores de clorofila extraível e de nitrogênio na folha de milho. Revista Brasileira de Fisiologia Vegetal, Lavras, v. 13, n. 2, p. 158-167, 2001.

BENDER, R. R.; HAEGELE, J. W.; RUFFO, M. L.; BELOW, F. E. Nutrient uptake, partitioning, and remobilization in modern transgenic insect-protected maize hybrids. Agronomy Journal, Madison, v. 105, n. 1, p. 161-170, 2013.

BORGHI, E.; MELLO, L. M. M.; CRUSCIOL, C. A. C. Adubação por área e por planta, densidade populacional e desenvolvimento do milho em função do sistema de manejo do solo. Acta Scientiarum Agronomy, Maringá, v. 26, n. 3, p. 337-345, 2004.

BRITO, M. E. B.; DE ARAÚJO FILHO, G. D.; WANDERLEY, J. A. C.; DE MELO, A. S.; DA COSTA, F. B.; FERREIRA, M. G. P. Crescimento, fisiologia e produção do milho doce sob estresse hídrico. Bioscience Journal, Uberlândia, v. 29, n. 5, p. 12441254, 2013.

Companhia Nacional de Abastecimento - CONAB. Acompanhamento da safra brasileira de grãos, Safra 2017/18 - Sétimo levantamento, Brasília, 2018. p. 1-139. Disponível em: https://www.conab.gov.br/index.php/info-agro/safras/graos. Acesso em: 20 abr. 2018

EMPRESA BRASILEIRA DE PESQUISA AGROPECUÁRIA - EMBRAPA. Sistema brasileiro de classificação de solos. 3. ed. Brasília, 2013. 353p.

ERNANI, P. R.; BAYER, C.; ALMEIDA, J. A. Mobilidade vertical de cátions influenciada pelo método de aplicação de cloreto de potássio em solos com carga variável. Revista Brasileira de Ciência do Solo, Viçosa, v. 31, n. 2, p. 393-402, 2007. 
GOTT, R. M.; AQUINO, L. A.; CARVALHO, A. M. X.; SANTOS, L. P. D.; NUNES, P. H. M. P.; COELHO, B. S. Índices diagnósticos para interpretação de análise foliar do milho. Revista Brasileira de Engenharia Agrícola e Ambiental, Campina Grande, v. 18, n. 11, p. 1110-1115, 2014.

MALAVOLTA, E.; VITTI, G. C.; OLIVEIRA, S. A. Princípios, métodos e técnicas de avaliação do estado nutricional. In: MALAVOLTA, E. (ed.). Avaliação do estado nutricional de plantas: Princípios e aplicações. $2^{\mathrm{a}}$ ed. Piracicaba: Potafos, 1997. p. 115-230.

MONTEZANO, Z. F.; CORAZZA, E. J.; MURAOKA, T. Variabilidade de nutrientes em plantas de milho cultivado em talhão manejado homogeneamente. Bragantia, Campinas, v. 67, n. 4, p. 969-976, 2008.

PRIMAVESI, O.; PRIMAVESI, A. C.; CÔRREA, L. A.; SILVA, A. G.; CANTARELLA, H. Lixiviação de nitrato em pastagens de coastcross adubada com nitrogênio. Revista Brasileira de Zootecnia, Viçosa, v. 53, n. 3; p. 683-690, 2006.

SANGOI, L.; BERNS, A. C.; ALMEIDA, M. L.; ZANIN, C. G.; SCHWEITZER, C. Características agronômicas de cultivares de trigo em resposta à época da adubação nitrogenada de cobertura. Ciência Rural, Santa Maria, v. 37, n. 6, p. 1564-1570, 2007.

SANTOS, L. P. D.; AQUINO, L. A.; NUNES, P. H. M. P.; XAVIER, F. O. Doses de nitrogênio na cultura do milho para altas produtividades de grãos. Revista Brasileira de Milho e Sorgo, Sete Lagoas, v. 12, n. 3, p. 270-279, 2013.

SETIYONO, T. D.; WALTERS, D. T.; CASSMAN, K. G.; WITT, C.; DOBERMANN, A. Estimating maize nutrient uptake requirements. Field Crops Research, Canberra, v. 118, n. 2, p. 158-168, 2010.

SICHOCKI, D.; GOTT, R. M.; FUGA, C. A. G.; AQUINO, L. A.; RUAS, R. A. A.; NUNES, P. H. P. M. Resposta do milho safrinha a doses de nitrogênio e fósforo. Revista Brasileira de Milho e Sorgo, Sete Lagoas, v. 34, n. 6, p. 1404-1411, 2014.

VALDERRAMA, M.; BUZETTI, S.; BENETT, C. G. S.; ANDREOTTI, M.; TEIXEIRA FILHO, M. C. M. Fontes e doses de NPK em milho irrigado sob plantio direto. Pesquisa Agropecuária Tropical, Goiânia, v. 41, n. 2, p. 254-263, 2011. 
ZÖRB, C.; T SENBAYRAM, M.; PEITERC, E. Potassium in agriculture - Status and perspectives. Journal of Plant Physiology, Parkville, v. 171, n. 9, p. 656-669, 2014.

Recebido em: 16/08/2017

Aceito em: 20/07/2018 